UDC 658.5

LBC 65.050

\title{
IMPROVEMENT OF THE ORGANIZATIONAL AND ECONOMIC MECHANISM OF ANTI-CRISIS MANAGEMENT AT INDUSTRIAL ENTERPRISES
}

\author{
Viktoriya V. Dyachkova \\ Donbass State Technical University, Alchevsk, Luhansk People's Republic \\ Natalya A. Podgornaya \\ Donbass State Technical University, Alchevsk, Luhansk People's Republic \\ Vladimir A. Kulik \\ Donbass State Technical University, Alchevsk, Luhansk People's Republic
}

\begin{abstract}
The present paper deals with the issues of anti-crisis management of an industrial enterprise. We provide a clear definition of anti-crisis management and the key problems that hinder it. Within the framework of solving these problems, we have improved the organizational and economic mechanism of anti-crisis management of an industrial enterprise through a new approach to assessing the effectiveness of anti-crisis measures and using dynamic programming methods to form an anti-crisis program.

The proposed mechanism is based on instant exclusion and fundamental diagnosis of the enterprise condition. The diagnosis lets reveal the reasons and prerequisites for the emergence of crisis situations, as well as the places of their possible occurrence, duration and complexity. We offer a list of measures as the next steps to overcome the crisis situations, to assess and compare them, and to form an effective anti-crisis program in the conditions of limited resources. The final stage consists in the implementation and monitoring of the designed anti-crisis program.

We pay special attention to the evaluation of the effectiveness of anti-crisis measures. The expert method for evaluating the effectiveness of the anti-crisis measures has been further described in the paper, which makes it possible to obtain an integral assessment that takes into account not only economic, but also resource, social, environmental and production-technological components. This approach is especially relevant for large industrial enterprises, which are responsible for replenishing the budget, for ecology and social tension. This integral indicator lies at the basis of the economic and mathematical model of the formation of optimal anti-crisis program developed under the present research. We suggest using the maximum efficiency gain obtained after implementing one of the program measures per unit of invested funds as a criterion of optimality.
\end{abstract}

Key words: organizational and economic mechanism, anti-crisis management, anti-crisis program, efficiency evaluation, optimization model.

\section{СОВЕРШЕНСТВОВАНИЕ} ОРГАНИЗАЦИОННО-ЭКОНОМИЧЕСКОГО МЕХАНИЗМА АНТИКРИЗИСНОГО УПРАВЛЕНИЯ ПРОМЫШЛЕННЫМ ПРЕДПРИЯТИЕМ

\author{
Виктория Викторовна Дьячкова \\ Донбасский государственный технический университет, г. Алчевск, Луганская Народная Республика
}

Наталья Александровна Подгорная

Донбасский государственный технический университет, г. Алчевск, Луганская Народная Республика 


\section{Владимир Александрович Кулик}

Донбасский государственный технический университет, г. Алчевск, Луганская Народная Республика

Аннотация. В данной статье рассмотрены вопросы антикризисного управления промышленным предприятием, в том числе уточнено понятие антикризисного управления и выявлены основные проблемы, препятствующие эффективному управлению. В рамках решения этих проблем авторами усовершенствован организационно-экономический механизм антикризисного управления промышленным предприятием за счет нового подхода к оценке эффективности антикризисных мероприятий и использования методов динамического программирования для формирования антикризисной программы.

В основе предложенного организационно-экономического механизма лежат экспресс- и фундаментальная диагностики состояния предприятия. В результате фундаментальной диагностики выявляются причины и предпосылки возникновения кризисных ситуаций, а также места их возможного возникновения, продолжительность и сложность. В качестве последующих этапов авторы предлагают формировать перечень мероприятий по преодолению кризисных ситуаций, проводить их оценку и сопоставление, затем формировать эффективную антикризисную программу в условиях ограниченных ресурсов. Завершающим этапом является реализация и контроль выработанной антикризисной программы.

Особое внимание авторами уделяется вопросам получения оценки эффективности антикризисных мероприятий. Дальнейшее развитие в статье получил экспертный метод оценки эффективности антикризисных мероприятий, позволяющий получать интегральную оценку, учитывающую не только экономическую, но и ресурсную, социальную, экологическую и производственно-технологическую составляющие. Данный подход особо актуален для крупных промышленных предприятий, которые ответственны за наполнение бюджета, экологию, социальную напряженность. Данный интегральный показатель ложится в основу разработанной авторами экономико-математической модели формирования оптимальной антикризисной программы. В качестве критерия оптимальности предлагается использовать максимизацию прироста эффективности от внедрения включенного в программу мероприятия на единицу вложенных средств.

Ключевые слова: организационно-экономический механизм, антикризисное управление, антикризисная программа, оценка эффективности, оптимизационная модель.

\section{Проблема и ее связь}

\section{с научными и практическими задачами}

Деятельность современных промышленных предприятий неразрывно связана с неопределенностью и неустойчивостью их социально-экономического развития, что предопределяет возникновение кризисных явлений на предприятии [3, с. 129].

Следовательно, если перед предприятием стоит задача непрерывного развития, то и управление этим предприятием должно быть антикризисным. Антикризисное управление должно носить системный характер и осуществляться непрерывно. Узким местом антикризисного управления является проблема предвидения и распознавания предкризисных явлений. От ее решения во многом зависит успешность предотвращения кризиса и качество управления предприятием. Однако не все кризисы можно предотвратить, некоторые из них предприятию необходимо преодолеть, пережить [7, с. 114].
Как отмечено выше, неопределенность внешней среды и постоянное изменение условий функционирования промышленных предприятий обусловливают возрастание кризисных ситуаций и, соответственно, тормозят их развитие. В результате отечественный промышленный комплекс значительно отстает по качественным и количественным показателям от развитых стран мира. Необходимость обеспечения стабильного функционирования и управления промышленными предприятиями в кризисных условиях обусловливает потребность в соответствующем организационноэкономическом механизме.

На сегодняшний день проблемами антикризисного управления занимаются многие зарубежные и отечественные ученые. Так, исследованию сущности трактовки антикризисного управления, его функций и принципов посвятили свои научные публикации следующие авторы: Ю.А. Арутюнов, К.В. Балдин, А.О. Блинов, Е.П. Жарковская, В.М. Захаров, Н.Ю. Кругло- 
ва, А.В. Мурычев, В.И. Орехов, В.М. Распопов, В.В. Распопов, И.В. Сергеев, Э.А. Уткин, В.А. Черненко и другие.

Изучению форм и методов антикризисного управления, закономерностей их проявления, посвятили свои работы многие российские ученые С.А. Беляев, А.М. Букреев, А.П. Градов, В.П. Кириченко, Э.М. Коротков, И.А. Кошкин, В.Н. Гончаров, Ю.М. Осипов, В.М. Родионова и другие. За рубежом данными вопросами занимались: Альбрехт Стив, Стивен Финк, Хит Роберт, С. Майерс и многие другие.

Оценке эффективности антикризисного управления на предприятии посвящено большое количество публикаций как отечественных, так и зарубежных ученых: Н.Д. Гуськова, Н.В. Никитина, Г.Б. Юнг, Л.И. Скибицкая, М.Х. Мескон, М. Альберт, Ф. Хедоури, А.Т. Зуб, В.О. Василенко, Л.О. Лигоненко, В.И. Кошкин, И.А. Бланк и другие.

Большое количество публикаций по теме антикризисного управления с одной стороны свидетельствует о серьезной проработанности данной тематики, а с другой - о повышенном к ней интересе, обусловленном важностью и сложностью данной проблемы, высокой практической значимостью для бизнеса.

\section{Изложение материала и его результаты}

Изучение основ антикризисного управления показало, что современное понимание данного понятия не является однородным и однозначным, то есть в экономической литературе нет единого мнения относительно определения сущности понятия «антикризисное управление».

Одни считают, что антикризисное управление - это совокупность профилактических мероприятий, направленных на предотвращение кризиса, осуществляемых постоянно и непрерывно. Другие авторы отмечают, что применение антикризисного управления необходимо лишь в период кризиса $[1$, с. $7-8 ; 6]$.

Под антикризисным управлением в статье будем понимать такой сложный процесс, включающий предвидение возможности возникновения кризисной ситуации, выявление кризиса и анализ симптомов его возникнове- ния, максимальное уменьшение негативного воздействия кризиса на систему, адекватный выбор инструментов для скорейшего выхода из кризиса.

Данное определение ложится в основу разработки организационно-экономического механизма антикризисного управления промышленным предприятием, базовыми составляющими которого должны быть следующие этапы: диагностика предприятия на наличие кризисного состояния (предкризисного), поиск антикризисных мероприятий, оценка эффективности предложенных мероприятий, реализация и контроль антикризисной программы [4; 9].

Графическое представление организационно-экономического механизма антикризисного управления промышленным предприятием приведено на рисунке 1 .

Рассмотрим более детально каждый из предлагаемых этапов:

I. Диагностика кризисного состояния и угрозы банкротства. Целью данного этапа является раннее определение наличия и глубины кризисных процессов на предприятии. Первоначально производится экспресс-диагностика, основу которой составляет оценка финансовой устойчивости и анализ изменения плановых показателей предприятия. Ее необходимо проводить ежемесячно, в случае выявления симптомов кризиса на предприятии, переходят к фундаментальной диагностике. Данная диагностика позволяет определить объекты наблюдения «кризисного поля», проанализировать отдельные стороны кризисного финансового развития предприятия, а также оценить масштабы кризисного состояния на предприятии [8, c. 198-201]. Результатом данного этапа является отчет об оценке состояния предприятия и причинах кризиса.

II. Поиск антикризисных мероприятий. Целью этого этапа является определения совокупности мероприятий для выхода из кризисной ситуации. На основе выявленных причин кризиса и текущей оценки состояния предприятия предлагаются группы мероприятий. Результатом этапа является перечень мероприятий, которые предприятие может реализовать в рамках антикризисного управления. 


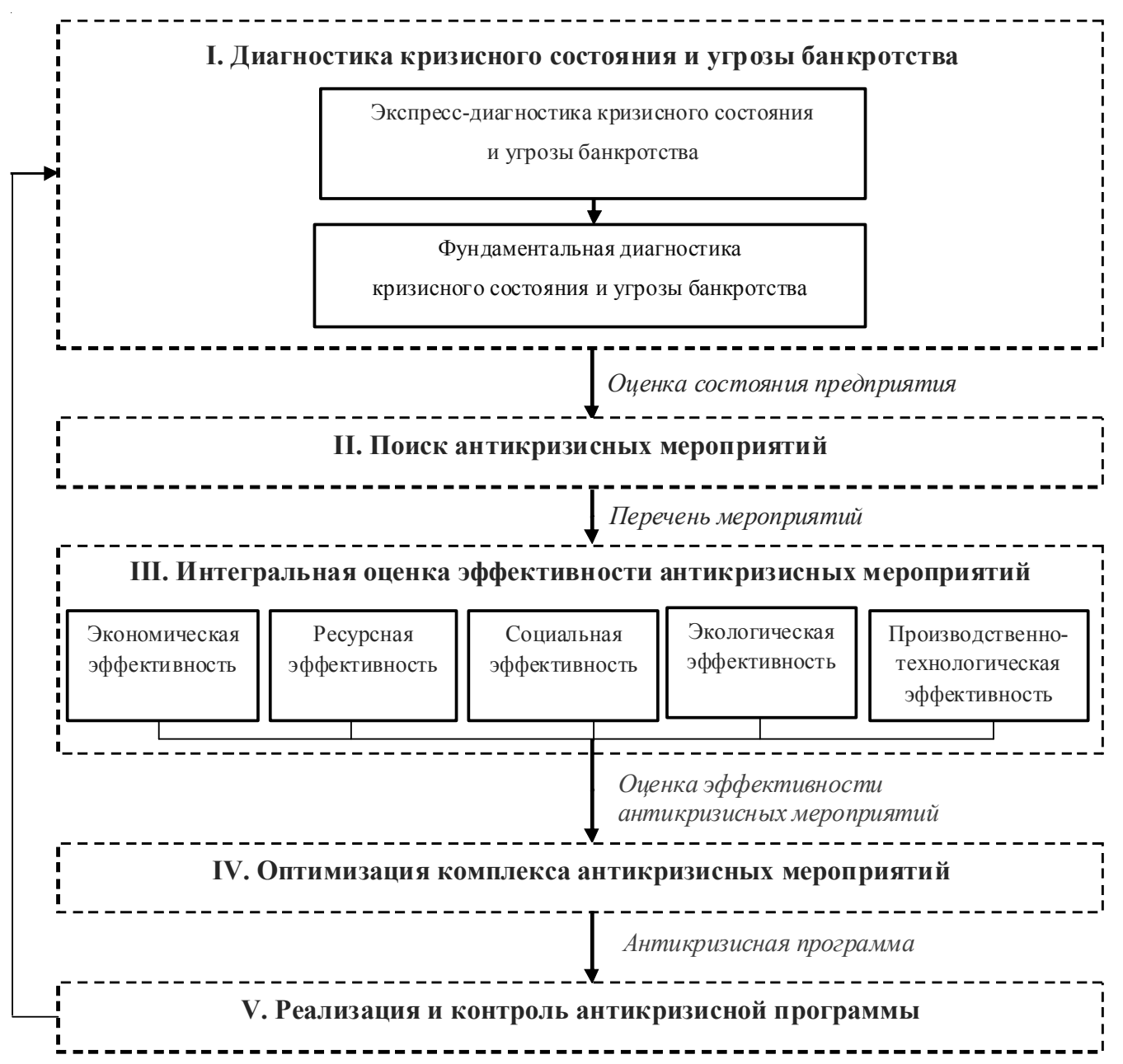

Рис.1. Организационно-экономический механизм антикризисного управления промышленным предприятием

III. Интегральная оценка эффективности антикризисных мероприятий. Целью этого этапа является оценка эффективности предлагаемых мероприятий.

Следует учитывать, что реализация антикризисных мероприятий влечет за собой не только изменение финансовых и экономических показателей деятельности предприятия, но и изменения в социальной, производственной, экологической сферах деятельности.

Выделим следующие виды эффективности входящие в состав интегральной оценки антикризисных мероприятий:

- экономическая эффективность (отражает насколько изменилась прибыльность предприятия от внедрения мероприятия, а также тенденции экономического роста на предприятии);

- ресурсная эффективность (оценивает эффективность использования различных видов ресурсов предприятия);
- социальная эффективность (оценивает социальные выгоды, уровень заработной платы, коэффициент текучести кадров, уровень жизни и др.);

- экологическая эффективность (определяется наличием и размером экологической выгоды от внедрения данного мероприятия). С учетом специфики металлургического предприятия, в ее состав необходимо включать уровень выбросов загрязняющих веществ в атмосферу и воду, а также уровни использования возвратных вод, коксового и конверторного газа для генерации электроэнергии;

- производственно-технологическая (эффективность определяется результативностью производства, она свидетельствует не о темпах прироста объемов производства, а о том, какой ценой, какими затратами ресурсов достигается этот прирост) [5, с. 166-168]. 
Таким образом, необходимо решить задачу оценки каждого отдельного вида эффективности и получения интегральной оценки. Для решения этой задачи предлагается по каждому оцениваемому мероприятию придерживаться следующего алгоритма расчета.

\section{Алгоритм оценки эффективности антикризисного мероприятия}

1. Определение и формирование перечня факторов (показателей) определяющих вид $u_{i}$-й эффективности. Для корректности расчета и сравнения мероприятий система показателей для их оценки должна быть единой.

Показатели, характеризующие соответствующий вид эффективности, приведены в таблице 1 .

Здесь часто возникают сложности оценки влияния отдельного антикризисного мероп- риятия на показатели эффективности всего предприятия. Подобные проблемы решаются ситуационно, оцениваются словесно на основе опыта экспертов, так как получить количественную оценку данных показателей очень затруднительно.

2. Получение оценки $u_{i j}$ для каждого $j$-го показателя по $i$-му виду эффективности в баллах. Оценка эффективности каждого мероприятия производится экспертным путем на основании анкетирования, данные рассчитываются в баллах от 0 до 100. Каждый показатель включенный в таблицу 1 оценивается экспертами по степени его влияния на прирост эффективности того или иного показателя. Авторами предлагается следующая градация степени влияния внедрения мероприятия на результирующие показатели деятельности предприятия:

1) не влияет (0-20 баллов);

2) слабо влияет (20-40 баллов);

Таблица 1

\section{Показатели, характеризующие каждый вид эффективности}

\begin{tabular}{|c|c|}
\hline Вид эффективности & Показатель \\
\hline \multirow{5}{*}{$\begin{array}{l}\text { 1. Экономиче- } \\
\text { ская }\left(u_{1}\right)\end{array}$} & Соотношение цены единицы продукции предприятия к среднеотраслевой цене $\left(u_{11}\right)$ \\
\hline & Рентабельность продукции, \% $\left(u_{12}\right)$ \\
\hline & Коэффициент покрытия $\left(u_{13}\right)$ \\
\hline & Затраты на 1 руб. товарной продукции $\left(u_{14}\right)$ \\
\hline & Производительность труда $\left(u_{15}\right)$ \\
\hline \multirow[t]{5}{*}{ 2. Ресурсная $\left(u_{2}\right)$} & Материальные затраты в общем объеме себестоимости продукции $\left(u_{21}\right)$ \\
\hline & Доля брака продукции $\left(u_{22}\right)$ \\
\hline & Уровень использования сырья и других ресурсов $\left(u_{23}\right)$ \\
\hline & Утилизация отходов $\left(u_{24}\right)$ \\
\hline & Возможности использования отходов производства $\left(u_{25}\right)$ \\
\hline \multirow[t]{5}{*}{ 3. Социальная $\left(u_{3}\right)$} & Зарплатоотдача $\left(u_{31}\right)$ \\
\hline & Уровень жизни работников $\left(u_{32}\right)$ \\
\hline & $\begin{array}{l}\text { Повышение эффективности мер, направленных на укрепление и защиту здоро- } \\
\text { вья персонала }\left(u_{33}\right)\end{array}$ \\
\hline & Коэффициент текучести кадров $\left(u_{34}\right)$ \\
\hline & Результативность работников (финансовая результативность труда) $\left(u_{35}\right)$ \\
\hline \multirow[t]{5}{*}{ 4. Экологическая $\left(u_{4}\right)$} & Уровень выбросов в атмосферу $\left(u_{41}\right)$ \\
\hline & Уровень выбросов загрязняющих веществ в воду $\left(u_{42}\right)$ \\
\hline & Уровень складирования твердых веществ $\left(u_{43}\right)$ \\
\hline & Уровень использования возвратных вод $\left(u_{44}\right)$ \\
\hline & $\begin{array}{l}\text { Уровень использования коксового и конверторного газа для генерации электро- } \\
\text { энергии }\left(u_{45}\right)\end{array}$ \\
\hline \multirow{5}{*}{$\begin{array}{l}\text { 5. Производственно- } \\
\text { технологическая }\left(u_{5}\right)\end{array}$} & Уровень механизации и автоматизации $\left(u_{51}\right)$ \\
\hline & Коэффициент использования производственных мощностей предприятия $\left(u_{52}\right)$ \\
\hline & Средний возраст технологических процессов $\left(u_{53}\right)$ \\
\hline & Коэффициент соотношения реализованной и произведенной продукции $\left(u_{54}\right)$ \\
\hline & Материалоемкость единицы продукции $\left(u_{55}\right)$ \\
\hline
\end{tabular}

Примечание. Составлено авторами. 
3) влияет (40-60 баллов);

4) сильно влияет (60-80 баллов);

5) очень сильно влияет (80-100 баллов).

В качестве экспертов следует привлекать различного профиля специалистов, от этого будет зависеть точность оценки (директора по производству, главного экономиста, финансиста-аналитика, директора отдела кадров и др.). Также рекомендуется привлекать независимых экспертов. Возможно расширение экспертной группы в зависимости от специфики оцениваемого мероприятия.

3. Формирование системы предпочтений факторов на каждом уровне иерархии. Система предпочтений - это система, в которой каждый фактор на соответствующем уровне иерархии должен быть поставлен в отношении к следующему в степени безразличия либо предпочтения. Для оценки эффективности антикризисного мероприятия авторами предлагается двухуровневая система предпочтений факторов, где верхний уровень иерархии характеризуется видами эффективности, а нижний уровень - показателями в рамках каждого вида эффективности. Так, например, если в текущей ситуации увеличение экономической эффективности предпочтительнее всех остальных видов эффективности, а остальные виды эффективности, в свою очередь, равнозначны (безразличны) для предприятия, то система предпочтений факторов на верхнем уровне будет иметь вид $u_{1} \succ u_{2} \approx u_{3} \approx u_{4} \approx u_{5}$. Подобная система предпочтений также строится для показателей по каждому виду эффективности. Таким образом, каждое антикризисное мероприятие будет характеризоваться индивидуальной системой предпочтений, но едиными для всех мероприятий показателями эффективности (см. табл. 1).

4. Получение весов с помощью правил Фишберна. Система предпочтений положена в основу получения весов, что позволяет в рамках одной системы показателей эффективности для всех антикризисных мероприятий получить индивидуальные значения весов.

5. Получение интегральной оценки.

Проведя расчет весовых коэффициентов единичных показателей, можно приступать к расчету оценки каждого вида эффективности антикризисного мероприятия:

$$
u_{i}=\sum_{j=1}^{n} u_{i j} \cdot \omega_{j},
$$

где $u_{i}$ - оценка $i$-го вида эффективности; $\omega_{j}-$ вес $j$-го показателя оценки эффективности антикризисных мероприятий; $u_{i j}$ - единичный $j$-й показатель $i$-го вида эффективности оценки антикризисного мероприятия.

Показатель интегральной оценки эффективности антикризисного мероприятия имеет следующий вид:

$$
I=\sum_{i=1}^{5} u_{i} \cdot \omega_{i},
$$

где $I$ - интегральный показатель оценки эффективности антикризисного мероприятия; $\omega_{i}-$ коэффициент значимости $i$-го вида эффективности, при этом $\sum_{i=1}^{5} \omega_{i}=1$.

Градация значений интегрального показателя эффективности антикризисного мероприятия представлена в таблице 2.

\section{Градация значений интегрального показателя эффективности антикризисного мероприятия}

\begin{tabular}{|c|c|}
\hline Интервал значений, $I$ & Классификация уровня параметра \\
\hline $0 \leq I \leq 20$ & Очень низкая эффективность \\
\hline $20 \leq I \leq 40$ & Низкая эффективность \\
\hline $40 \leq I \leq 60$ & Средняя эффективность \\
\hline $60 \leq I \leq 80$ & Высокая эффективность \\
\hline $80 \leq I \leq 100$ & Очень высокая эффективность \\
\hline
\end{tabular}

Примечание. Составлено авторами.

В результате проведения III этапа мы имеем интегральную оценку эффективности каждого мероприятия, частично или полностью разрешающего кризисную ситуацию. При этом одно и то же мероприятие может в различной степени решать разные кризисные ситуации, что влечет за собой связь «многие ко многим» между сущностями «антикризисное мероприятие» и «кризисная ситуация».

IV. Оптимизация комплекса антикризисных мероприятий. Целью этого этапа является формирование такой программы финансирования антикризисных мероприятий, при которой в условиях ограниченности ресурсов со- 
вокупная эффективность внедряемых антикризисных мероприятий будет максимальная.

На крупном промышленном предприятии большое количество $(m)$ кризисных ситуаций может решаться большим количеством $(n)$ мероприятий. Данная ситуация приводит к сложной задаче выбора и анализа перечня наиболее эффективных мероприятий в условиях ограниченности ресурсов. Ее можно предварительно решить (упростить), сформировав таблицу с перечнем кризисных ситуаций и соответствующих антикризисных мероприятий, затем ранжировав мероприятия по количеству решаемых ими кризисных ситуаций.

Если существует обстановка, в которой кризисная ситуация решается несколькими антикризисными мероприятиями с различной эффективностью и стоимостью реализации, и при этом частичное финансирование мероприятия допустимо, то построение модели формирования антикризисной программы целесообразно проводить в соответствии с алгоритмом моделирования задач динамического программирования.

Рассмотрим процесс распределения средств между антикризисными мероприятиями как $n$-шаговый процесс, где количество шагов равно количеству мероприятий. В качестве $k$-го шага выберем количество мероприятий, которым выделяются денежные средства: на 1-м шаге все средства инвестируют в первое мероприятие, на 2-м - в первое и второе мероприятие, на $n$-м - в $1,2, \ldots n$ мероприятие.

Пусть $S$ - начальное состояние системы (запас средств в начале каждого шага). $X_{k}^{*}(S)$ - условно-оптимальное управление на $k$-м шаге (объем средств, выделяемых на $k$-м шаге $k$-му мероприятию для обеспечения максимально возможного прироста интегрального показателя эффективности антикризисного управления). Тогда оптимальный план распределения средств для любой группы антикризисных мероприятий должен обладать свойством, что каким бы не был объем выделенных средств предыдущим мероприятиям, распределение средств для оставшихся мероприятий должно быть оптимальным с точки зрения максимизации общего прироста интегрального показателя эффективности антикризисного управления. Вы- числительный процесс следует выполнять по прямой схеме.

Следовательно, целевая функция будет иметь вид:

$$
F=\sum_{k=1}^{n} g_{k}\left(x_{k}\right) \rightarrow \max
$$

где $g_{k}\left(x_{k}\right)$ - возможный прирост интегрального показателя эффективности антикризисного управления на $k$-ом мероприятии в зависимости от объема вложенных средств $x_{k}$.

$\mathrm{B}$ качестве показателя эффективности антикризисного управления возьмем значение интегрального показателя эффективности n-го мероприятия на единицу вложенных средств. Будем считать, что частичное финансирование мероприятия допустимо и его эффективность будет прямо пропорциональна количеству вложенных средств. Тогда прирост интегрального показателя эффективности антикризисного управления будет считаться по формуле:

$$
g_{n}(S)=\frac{I}{K B} \cdot S, \text { баллы }
$$

где $K B$ - капитальные вложения на реализацию мероприятия, руб.; $S$ - размер вложенных средств, руб.

Необходимо отметить, что если сумма вложенных средства $S=K B$, то тогда показатель эффективности принимает максимальное значение, а если $S>K B$, то прирост денежных средств не будет способствовать увеличению интегрального показателя эффективности антикризисного управления.

Рекуррентное соотношение Беллмана для задачи оптимального распределения средств между антикризисными мероприятиями будет иметь вид:

$$
F_{k}^{*}(S)=\max _{X \leq S}\left\{g_{k}(x)+F_{k-1}^{*}(S-x)\right\},
$$

где $F_{k}^{*}(S)$ - условно-оптимальный эффект на $k$-м шаге, при условии, что до данного шага уровень запаса средств был равен $S$.

На основании соотношения (5) последовательно для каждого шага осуществляется условная, а затем безусловная оптимизация процесса с использованием соответствующих оптимизационных таблиц [2, с. 302-314]. 
Результатом IV этапа является формирование оптимальной программы финансирования антикризисных мероприятий по критерию максимизации интегрального показателя эффективности антикризисного управления.

V. Реализация и контроль антикризисной программы. Целью данного этапа является своевременное выполнение разработанной антикризисной программы, а также формирование обратной связи для предупреждения дальнейших кризисных ситуаций.

Практическая реализация предложенного выше организационно-экономического механизма антикризисного управления осуществлялась на базе филиала № $123 \mathrm{AO}$ «Внешторгсервис». В результате анализа деятельности данного предприятия авторами были выявлены предпосылки для возникновения кризисных ситуаций, а также установлены соответствующие антикризисные мероприятия (табл. 3).

Из предложенного списка таблицы 3 выберем мероприятия, предотвращающие наибольшее количество кризисных ситуаций:

- мероприятие 1 - модернизация системы утилизации конверторных газов;
- мероприятие 2 - монтирование компрессорных агрегатов для воздухоразделительных установок «Air Liquide»;

- мероприятие 3 - применение технологии вдувания пылеугольного топлива.

На антикризисную программу выделяется 3000 млн руб. Необходимо составить программу финансирования мероприятий, исходя из критерия максимизации интегрального показателя эффективности антикризисного управления. Капитальные затраты на реализацию мероприятий составляют 1000, 2000, 1500 млн руб. соответственно.

Используя предложенный алгоритм оценки эффективности антикризисного мероприятия, рассчитаем интегральные показатели эффективности по трем выбранным выше антикризисным мероприятиям (см. табл. 4).

Рассчитаем прирост интегрального показателя эффективности антикризисных мероприятий по формуле 3 и сведем в таблицу 5.

Используя рекуррентное соотношение (5) были построены оптимизационные таблицы и результаты условной оптимизации сведены в таблицу 6.

\section{Мероприятия для предотвращения возникновения кризисных явлений}

\begin{tabular}{|c|c|}
\hline Предпосылки кризисной ситуации & Мероприятия \\
\hline \multirow[t]{3}{*}{ Высокая себестоимость продукции } & Модернизация системы утилизации конверторного газа \\
\hline & $\begin{array}{l}\text { Монтаж компрессорных агрегатов для воздухоразделительных устано- } \\
\text { вок «Air Liquide» }\end{array}$ \\
\hline & Применение технологии вдувания пылеугольного топлива \\
\hline \multirow[t]{3}{*}{ Энергоемкость } & $\begin{array}{l}\text { Внедрение новых образцов оборудования и инновационных технологий по } \\
\text { использованию вторичных энергоресурсов }\end{array}$ \\
\hline & Применение технологии вдувания пылеугольного топлива \\
\hline & Внедрение газовых бескомпрессорных турбин утилизации \\
\hline \multirow[t]{2}{*}{ Загрязнение окружающей среды } & Модернизация системы утилизации конверторного газа \\
\hline & Внедрение установок утилизации тепла дымовых газов доменных печей \\
\hline $\begin{array}{l}\text { Низкое содержание металла в } \\
\text { сырье }\end{array}$ & Технология и оборудование для брикетирования отходов \\
\hline \multirow{3}{*}{$\begin{array}{l}\text { Высокие внутренние цены на } \\
\text { энергоносители и электроэнер- } \\
\text { гию }\end{array}$} & Модернизация системы утилизации конверторного газа \\
\hline & $\begin{array}{l}\text { Внедрение новых образцов оборудования и инновационных технологий по } \\
\text { использованию вторичных энергоресурсов }\end{array}$ \\
\hline & $\begin{array}{l}\text { Монтаж компрессорных агрегатов для воздухоразделительных устано- } \\
\text { вок «Air Liquide» }\end{array}$ \\
\hline \multirow{3}{*}{$\begin{array}{l}\text { Износ основных производствен- } \\
\text { ных мощностей и низкий уровень } \\
\text { их использования }\end{array}$} & Применение технологии вдувания пылеугольного топлива \\
\hline & Модернизация системы утилизации конверторного газа \\
\hline & $\begin{array}{l}\text { Монтаж компрессорных агрегатов для воздухоразделительных устано- } \\
\text { вок «Air Liquide» }\end{array}$ \\
\hline
\end{tabular}

Примечание. Составлено авторами. 
В.В. Дьячкова, Н.А. Подгорная, В.А. Кулик. Совершенствование организационно-экономического механизма

Оптимальный вариант распределения средств между тремя мероприятиями:

- инвестиции в мероприятие 1 составят 0 млн руб.;

- инвестиции в мероприятие 2 составят 2000 млн руб.;
- инвестиции в мероприятие 3 составят 1000 млн руб.

При таком распределении средств будет получен максимальный прирост показателя эффективности антикризисного управления, который составит 162,59 балла.

\section{Результаты расчетов интегрального показателя эффективности антикризисного управления}

Таблища 4

\begin{tabular}{|c|c|c|c|c|c|c|}
\hline \multirow{3}{*}{ Эффективность } & \multicolumn{6}{|c|}{ Наименование } \\
\hline & \multicolumn{2}{|c|}{ Мероприятие 1} & \multicolumn{2}{|c|}{ Мероприятие 2} & \multicolumn{2}{|c|}{ Мероприятие 3} \\
\hline & $\mathrm{Bec}$ & Оценка & $\mathrm{Bec}$ & Оценка & $\mathrm{Bec}$ & Оценка \\
\hline Экономическая & $\mathbf{0 , 2 7 2}$ & 72,5 & $\mathbf{0 , 2}$ & 89,52 & $\mathbf{0 , 2 5}$ & 64,34 \\
\hline $\begin{array}{l}\text { Соотношение цены единицы продукции } \\
\text { предприятия к среднеотраслевой цене }\end{array}$ & 0,3 & 74 & 0,286 & 90 & 0,333 & 59 \\
\hline Рентабельность продукции & 0,2 & 69 & 0,286 & 89 & 0,267 & 65 \\
\hline Коэффициент покрытия & 0,2 & 77 & 0,143 & 86 & 0,2 & 68 \\
\hline Затраты на 1 руб. товарной продукции & 0,2 & 76 & 0,143 & 94 & 0,133 & 67 \\
\hline Производительность труда & 0,1 & 59 & 0,143 & 88 & 0,067 & 72 \\
\hline \begin{tabular}{|l} 
Ресурсная \\
\end{tabular} & $\mathbf{0 , 2 7 2}$ & 78,14 & 0,2 & 85,4 & $\mathbf{0 , 2 5}$ & 67,63 \\
\hline $\begin{array}{l}\text { Материальные затраты в общем объеме се- } \\
\text { бесто имости продукции }\end{array}$ & 0,333 & 78 & 0,2 & 87 & 0,25 & 65 \\
\hline Доля брака продукции & 0,267 & 80 & 0,2 & 85 & 0,25 & 63 \\
\hline $\begin{array}{l}\text { Уровень использования сырья и других ре- } \\
\text { сурсов }\end{array}$ & 0,2 & 76 & 0,2 & 90 & 0,25 & 70 \\
\hline Утилизация отходов & 0,133 & 72 & 0,2 & 87 & 0,125 & 67 \\
\hline $\begin{array}{l}\text { Возможности использования отходов произ- } \\
\text { водства }\end{array}$ & 0,067 & 90 & 0,2 & 78 & 0,125 & 78 \\
\hline Социальная & 0,182 & 76,53 & 0,2 & 86 & 0,25 & 67,4 \\
\hline Зарплатоотдача & 0,333 & 76 & 0,25 & 90 & 0,3 & 65 \\
\hline Уровень жизни работников & 0,267 & 71 & 0,25 & 75 & 0,2 & 69 \\
\hline $\begin{array}{l}\text { Повышение эффективности мер, направлен- } \\
\text { ных на укрепление и защиту здоровья пер- } \\
\text { сонала }\end{array}$ & 0,2 & 79 & 0,25 & 93 & 0,2 & 60 \\
\hline Коэффициент текучести кадров & 0,133 & 82 & 0,125 & 88 & 0,2 & 78 \\
\hline $\begin{array}{l}\text { Результативность работников (финансовая } \\
\text { результативность труда) }\end{array}$ & 0,067 & 83 & 0,125 & 84 & 0,1 & 65 \\
\hline Экологическая & 0,182 & 79,2 & 0,2 & 88,6 & 0,125 & 60,13 \\
\hline Уровень выбросов в атмосферу & 0,2 & 80 & 0,3 & 90 & 0,333 & 60 \\
\hline $\begin{array}{l}\text { Уровень выбросов загрязняющих веществ в } \\
\text { воду }\end{array}$ & 0,2 & 85 & 0,2 & 92 & 0,267 & 58 \\
\hline Уровень складирования твердых веществ & 0,2 & 81 & 0,2 & 89 & 0,2 & 54 \\
\hline Уровень использования возвратных вод & 0,2 & 70 & 0,2 & 85 & 0,133 & 71 \\
\hline $\begin{array}{l}\text { Уровень использования коксового и конвер- } \\
\text { торного газа для генерации электроэнергии }\end{array}$ & 0,2 & 80 & 0,1 & 84 & 0,067 & 66 \\
\hline Производственно-технологическая & 0,090 & 68,71 & $\mathbf{0 , 2}$ & 85,94 & $\mathbf{0 , 1 2 5}$ & $\mathbf{5 5 , 3}$ \\
\hline Уровень механизации и автоматизации & 0,333 & 76 & 0,333 & 78 & 0,3 & 51 \\
\hline $\begin{array}{l}\text { Коэффициент использования производст- } \\
\text { венных мощностей предприятия }\end{array}$ & 0,222 & 70 & 0,267 & 92 & 0,2 & 59 \\
\hline Средний возраст технологических процессов & 0,222 & 60 & 0,2 & 89 & 0,2 & 58 \\
\hline $\begin{array}{l}\text { Коэффициент соотношения реализованной и } \\
\text { произведенной продукции }\end{array}$ & 0,111 & 68 & 0,133 & 90 & 0,2 & 53 \\
\hline Материалоемкость единицы продукции & 0,111 & 63 & 0,067 & 84 & 0,1 & 60 \\
\hline $\begin{array}{c}\text { Интегральный показатель оценки } \\
\text { эффективности }\end{array}$ & & & & & & \\
\hline
\end{tabular}

Примечание. Составлено авторами. 


\section{Прирост интегрального показателя эффективности антикризисных мероприятий на предприятии}

\begin{tabular}{|c|c|c|c|}
\hline \multirow{2}{*}{$\begin{array}{c}\text { Денежные средства, } \\
\text { млн руб., } S\end{array}$} & \multicolumn{3}{|c|}{ Прирост показателя эффективности антикризисных мероприятий, баллы } \\
\cline { 2 - 4 } & $g_{I}(I)$ & $g_{2}(I)$ & $g_{3}(I)$ \\
\hline 0 & 0 & 0 & 0 \\
\hline 500 & 37,75 & 21,77 & 21,42 \\
\hline 1000 & 75,50 & 43,55 & 42,85 \\
\hline 1500 & 75,50 & 65,32 & 64,27 \\
\hline 2000 & 75,50 & 87,09 & 64,27 \\
\hline 2500 & 75,50 & 87,09 & 64,27 \\
\hline 3000 & 75,50 & 87,09 & 64,27 \\
\hline
\end{tabular}

Примечание. Составлено авторами.

Таблица 6

Сводная таблица результатов оптимизации по критерию максимизации интегрального показателя эффективности антикризисного управления

\begin{tabular}{|c|c|c|c|c|c|c|}
\hline 0 & $F_{1}{ }^{*}(I)$ & $X_{1}{ }^{*}(S)$ & $F_{2}{ }^{*}(I)$ & $X_{2}{ }^{*}(S)$ & $F_{3}{ }^{*}(I)$ & $X_{3}{ }^{*}(S)$ \\
\hline 0 & 0 & 0 & 0 & 0 & 0 & 0 \\
\hline 500 & 37,75 & 500 & 37,75 & 0 & 37,75 & 0 \\
\hline 1000 & $\mathbf{7 5 , 5}$ & $\mathbf{1 0 0 0}$ & 75,5 & 0 & 75,5 & 0 \\
\hline 1500 & 75,5 & 1500 & 97,27 & 500 & 97,27 & 0 \\
\hline 2000 & 75,5 & 2000 & 119,05 & 1000 & 119,05 & 0 \\
\hline 2500 & 75,5 & 2500 & 140,82 & 1500 & 140,82 & 0 \\
\hline 3000 & 75,5 & 3000 & $\mathbf{1 6 2 , 5 9}$ & $\mathbf{2 0 0 0}$ & $\mathbf{1 6 2 , 5 9}$ & $\mathbf{0}$ \\
\hline
\end{tabular}

Примечание. Составлено авторами.

Выводы. В ходе исследования был усовершенствован организационно-экономический механизм антикризисного управления промышленным предприятием за счет нового подхода к оценке эффективности антикризисных мероприятий и использования методов динамического программирования. Предложен метод оценки эффективности антикризисных мероприятий, учитывающий экономическую, ресурсную, социальную, экологическую и производственно-технологическую составляющие. Разработана модель формирования оптимальной программы финансирования антикризисных мероприятий, позволяющая максимизировать интегральный показатель эффективности антикризисного управления.

\section{СПИСОК ЛИТЕРАТУРЫ}

1. Ал-Ламі, Х. М. Формування організаційно-економічного механізму антикризового управління підприємством : автореф. дис. ... канд. екон. наук : 08.00.04 / Ал-Ламі Хайдер Мухсін Абдулазіз. Херсон, 2017. - 20 c.

2. Беллман, Р. Прикладные задачи динамического программирования : пер. с англ. / Р. Беллман,
С. Дрейфус ; под ред. А.А. Первозванского. - М. : Наука, 1965. $-460 \mathrm{c}$.

3. Воробьев, А. А. Идентификация наличия и определение причин кризиса на промышленном предприятии / А. А. Воробьев // ПСЭ. - 2014. № 4 (52). - C. 127-130.

4. Золотова, В. А. Организационно-экономический механизм формирования программы антикризисного управления предприятием промышленности России : монография / В. А. Золотова. М. : Перо, 2013. - 165 c.

5. Кондратьева, К. В. Проблемы и критерии оценки эффективности механизма антикризисного управления на промышленных предприятиях / К. В. Кондратьева // Журнал экономической теории. - 2015. - № 1. - С. 165-169.

6. Крылов, А. Н. Особенности антикризисного управления в промышленной компании / А. Н. Крылов, Т. В. Кокорева // Вестник ГУУ. 2014. - № 8. - С. 51-55.

7. Михайлова, А. А. Сущность и содержание антикризисного управления / А. А. Михайлова, О. В. Ильичева // Вестник НГИЭИ. - 2014. № 7 (38). - С. 113-123.

8. Овсянников, С. В. Финансовый мониторинг как инструмент кризисо-устойчивого развития предприятия / С. В. Овсянников // Территория науки. -2015. - № 4. - С. 196-202. 
9. Пыткин, А. Н. Эффективная модель организационно-экономического механизма антикризисного управления промышленным предприятием / А. Н. Пыткин, К. В. Кондратьева // Вестник ПГУ. Серия: Экономика. - 2016. - № 1 (28). - С. 138-146.

\section{REFERENCES}

1. Al-Lami H.M. Formation of the organizational and economic mechanism of crisis management. Cand. econ. sci. abs. diss. Kherson, 2017. 20 p. (in Ukrainian)

2. Bellman R. Prikladnye zadachi dinamicheskogo programmirovaniya [Applied Problems of Dynamic Programming]. Moscow, Nauka Publ., 1965. 460 p.

3. Vorobyev A.A. Identifikatsiya nalichiya i opredelenie prichin krizisa na promyshlennom predpriyatii [Revealing the Crisis and Its Causes at Industrial Enterprises]. PSE, 2014, no. 5 (52), pp. 127-130.

4. Zolotova V.A. Organizatsionnoekonomicheskiy mekhanizm formirovaniya programmy antikrizisnogo upravleniya predpriyatiem promyshlennosti Rossii: monografiya [Organizational and Economic Mechanism of Developing the Program of Anti-Crisis Management of a Russian Industrial Enterprise]. Moscow, Pero Publ., 2013. 165 p.
5. Kondratyeva K.V. Problemy i kriterii otsenki effektivnosti mekhanizma antikrizisnogo upravleniya na promyshlennykh predpriyatiyakh [Problems and Criteria for Evaluating the Mechanism of Crisis Management at Industrial Enterprises]. Zhurnal ekonomicheskoy teorii, 2015, no. 1, pp. 165-169.

6. Krylov A.N., Kokoreva T.V. Osobennosti antikrizisnogo upravleniya $\mathrm{v}$ promyshlennoy kompanii [Features of Crisis Management in an Industrial Company]. Vestnik GUU, 2014, no. 8, pp. 51-55.

7. Mikhaylova A.A., Ilyicheva O.V. Sushchnost i soderzhanie antikrizisnogo upravleniya [The Essence and Content of Crisis Management]. Vestnik NGIEI, 2014, no. 7 (38), pp. 113-123.

8. Ovsyannikov S.V. Finansovyy monitoring kak instrument kriziso-ustoychivogo razvitiya predpriyatiya [Financial Monitoring as a Tool of CrisisSustainable Development of the Enterprise]. Territoriya nauki, 2015, no. 4, pp. 196-202.

9. Pytkin A.N., Kondratyeva K.V. Effektivnaya model organizatsionno-ekonomicheskogo mekhanizma antikrizisnogo upravleniya promyshlennym predpriyatiem [Effective Model of Organizational and Economic Mechanism of Anti-Crisis Management of an Industrial Enterprise]. Vestnik PGU. Seriya: Ekonomika, 2016, no. 1 (28), pp. 138-146.

\section{Information about the Authors}

Viktoriya V. Dyachkova, Candidate of Sciences (Economics), Associate Professor, Department of Economic Cybernetics and Information Technologies, Donbass State Technical University, Prosp. Lenina, 16, 94204 Alchevsk, Luhansk People's Republic, dyachkova.vika@gmail.com.

Natalya A. Podgornaya, Candidate of Sciences (Engineering), Senior Lecturer, Department of Economic Cybernetics and Information Technologies, Donbass State Technical University, Prosp. Lenina, 16, 94204 Alchevsk, Luhansk People's Republic, nataly.podgorna@gmail.com.

Vladimir A. Kulik, Master Student, Department of Economics and Management, Donbass State Technical University, Prosp. Lenina, 16, 94204 Alchevsk, Luhansk People’s Republic, kulickvladimir@yandex.ru.

\section{Информация об авторах}

Виктория Викторовна Дьячкова, кандидат экономических наук, доцент кафедры экономической кибернетики и информационных технологий, Донбасский государственный технический университет, пр. Ленина, 16, 94204 г. Алчевск, Луганская Народная Республика, dyachkova.vika@gmail.com.

Наталья Александровна Подгорная, кандидат технических наук, старший преподаватель кафедры экономической кибернетики и информационных технологий, Донбасский государственный технический университет, пр. Ленина, 16, 94204 г. Алчевск, Луганская Народная Республика, nataly.podgorna@gmail.com.

Владимир Александрович Кулик, студент кафедры экономики и управления, Донбасский государственный технический университет, пр. Ленина, 16, 94204 г. Алчевск, Луганская Народная Республика, kulickvladimir@yandex.ru. 